\title{
Potential for the Development of Productive Activities of the Russian Penal System in the Context of Achieving National Goals Under the Paris Climate Agreement
}

\author{
Sergey I. Mutovin* \\ Scientific Research Institute \\ of the Federal Penitentiary System \\ Moscow, Russian Federation \\ Siberian Federal University \\ Krasnoyarsk, Russian Federation
}

Received 11.07.2020, received in revised form 15.08.2021, accepted 14.09.2021

\begin{abstract}
One of the key tasks of the penal and correctional system is not only to socially isolate convicts and organize acceptable living conditions for them, but also to ensure their adequate resocialization after serving their sentence. The solution of this problem requires new approaches to the conduct of production activities by the institutions of the Federal Penitentiary Service of Russia. Among others, priority should be given to the areas of traditional economic specialization of the penitentiary system, which include, for example, logging and woodworking. The national contribution of the Russian Federation to the implementation of the goals of the Paris Climate Agreement implies the fullest possible use of the carbon-absorbing capacity of Russian forests. This task is solved, among other things, by a significant increase in the volume of artificial reforestation, which requires the development of a network of tree nurseries throughout the country. The article analyzes in detail the experience of a joint pilot project on forest nursery creation based on one of the institutions of the Federal Penitentiary Service with the participation of business association in the field of forest industry in Krasnoyarsk Krai. It is shown that the project is not only effective, but also has high indicators of economic efficiency, characterized by low payback period under the condition of ensuring decent working conditions for inmates. It emphasizes the importance of scientific and methodological support of the work performed by universities and research institutes, including within the program of creating world-class scientific and educational centers of the Ministry of Science and Higher Education of the Russian Federation.
\end{abstract}

Keywords: penitentiary system, penal system, Federal Penitentiary Service, Paris Climate Agreement, forestry, economic potential, socio-economic development.

Research area: economics.

(C) Siberian Federal University. All rights reserved

* Corresponding author E-mail address: smutovin@sfu-kras.ru 
Citation: Mutovin, S.I. (2021) Potential for the development of productive activities of the Russian penal system in the context of achieving national goals under the Paris Climate Agreement. J. Sib. Fed. Univ. Humanit. soc. sci., 14(11), 1746-1755. DOI: 10.17516/1997-1370-0854

\title{
Потенциал развития производственной деятельности российской системы исполнения наказаний в контексте достижения национальных целей в рамках Парижского климатического соглашения
}

\author{
С.И. Мутовин \\ Научно-исследовательский институт ФСИН России \\ Российская Федерация, Москва \\ Сибирский федеральный университет \\ Российская Федерачия, Красноярск
}

\begin{abstract}
Аннотация. Одной из ключевых задач уголовно-исполнительной системы является не только общественная изоляция осужденных и организация приемлемых бытовых условий их содержания, но и обеспечение их адекватной ресоциализации после отбытия наказания. Решение данной задачи требует новых подходов к ведению производственной деятельности учреждениями Федеральной службы исполнения наказаний России. В числе прочих приоритетное внимание следует обратить на сферы традиционной хозяйственной специализации уголовно-исполнительной системы, к числу которых относится, например, лесозаготовка и деревообработка. Национальный вклад Российской Федерации в реализацию целей Парижского климатического соглашения подразумевает максимально полное использование потенциала углерод-поглощающей способности российских лесов. Данная задача решается в том числе за счет существенного наращивания объемов искусственного лесовосстановления, которое требует развития сети лесопитомников на всей территории страны. В статье подробно проанализирован опыт реализации в Красноярском крае совместного пилотного проекта по созданию лесопитомника на базе одного из учреждений ФСИН при участии бизнес-ассоциации в сфере лесной промышленности. Показано, что проект не только результативен, но и имеет высокие показатели экономической эффективности, характеризуется низкими сроками окупаемости при обеспечении достойных условий труда осужденных. Подчеркивается важность развития научно-методического обеспечения выполняемых работ со стороны университетов и научных институтов, в том числе в рамках программы создания научно-образовательных центров мирового уровня Минобрнауки.
\end{abstract}

Ключевые слова: пенитенциарная система, уголовно-исполнительная система, Федеральная служба исполнения наказаний, Парижское климатическое соглашение, лесное хозяйство, экономический потенциал, социально-экономическое развитие.

Научная специальность: 08.00.05 - экономика и управление народным хозяйством. 


\section{Введение}

Гуманизация всех сфер общественной жизни задает новые условия для развития многих секторов экономики, социальной сферы, осуществления государственных функций различного уровня. Центральным элементом данной парадигмы является человек, его интересы и возможности личностного роста, гармонизированного с целями развития общества. Данная повестка должна стать ключевым элементом государственной политики, особенно в тех сферах, для которых прежде такие вопросы не поднимались. Ярким примером здесь является система исполнения наказаний, которая традиционно воспринимается в России как карательный орган. Такое восприятие по большей части справедливо характеризует историческое положение дел, но не должно сдерживать текущее и перспективное развитие. Необходима новая политика, которая будет направлена на глубинные изменения психологии участников системы, на создание стимулов к наиболее полной реализации ее общественной функции.

Необходимо помнить, что одной из ключевых задач уголовно-исполнительной системы является не только общественная изоляция осужденных и организация приемлемых бытовых условий их содержания, но и обеспечение их адекватной ресоциализации после отбытия наказания. В этих целях в учреждениях системы Федеральной службы исполнения наказаний (ФСИН) реализуется возможность ведения трудовой деятельности осужденными, не имеющими медицинских и иных противопоказаний к труду. За счет данной деятельности обеспечивается привитие первоначальных трудовых навыков, восстановление и сохранение профессиональных компетенций, которое создает условия для последующей интеграции отбывших наказание в гражданскую жизнь. Кроме того, в рамках работы уголовно-исполнительной системы осуществляется широкая образовательная деятельность. Тем не менее важен анализ структуры вышеописанной деятельности по отдельным профессиям, а также ее по- лезности в контексте текущих и перспективных потребностей рынка труда как в национальном масштабе, так и с учетом специфики отдельных регионов.

Представляется, что развитие Федеральной службы исполнения наказаний требует новых подходов не только к организации непосредственной текущей деятельности, но и к реализации перспективных проектов, в том числе направленных на решение национальных задач в различных сферах социально-экономического развития страны.

В числе прочих внимание следует обратить на сферы традиционной хозяйственной специализации системы, к числу которых относится, например, лесозаготовка и деревообработка. На сегодняшний день данная деятельность осуществляется преимущественно в первых переделах производственных цепочек на уровне самых простых видов продукции, что предопределяет существенный потенциал повышения эффективности использования трудовых ресурсов, достижения более высоких экономических результатов, а также решения задач стратегической повестки развития страны.

Исследования экономических проблем пенитенциарных систем в мировой литературе малочисленны. Редкими контрпримерами являются работы по отдельным штатам США (Connelley et al., 1993; Scott, Derrick, 2006; Bari, 2007; LeBaron, 2008), Нидерландов (Schmidt, Van de Walle, 2020; Lamasharipov et al., 2018), Индии (Das, Sarma, 2020). В странах бывшего СНГ экономические исследования пенитенциарных систем также редки (Ezrokh, 2017; Abutalipov et al., 2020; Vilkova, Timofeeva, 2018; Bohatyrova et al., 2020), что открывает пространство для проведения соответствующих работ, в том числе по России.

В настоящей работе дается краткая характеристика деятельности пенитенциарной системы в России с фокусом на потенциал хозяйственной деятельности заключенных, анализируются возможности тиражирования опыта отдельных проектов лесохозяйственного профиля для обеспече- 
ния стратегического балансирования общественных и государственных интересов.

\section{Общие сведения о деятельности}

\section{пенитенциарной системы в России}

По данным проекта World Prison Brief, по численности заключенных Россия занимает 5-е место в мире (471,5 тыс. чел.) после США (2,1 млн чел.), Китая (1,7 млн чел.), Бразилии (811,7 тыс. чел.) и Индии (478,6 тыс. чел.). Соотношение численности контингентов заключенных и отношения численности контингента заключенных на 100 тыс. чел. населения представлено на рис. 1.

Безусловным лидером численности контингента заключенных и доли в общей численности населения являются США. Аналогичные показатели для России находятся на уровне показателей Турции.

С 2015 г. численность заключенных в стране сократилась с 650 тыс. чел. в 2015 г. до 470 тыс. чел. в 2021 г., т. е. на 27,7 \%. Общее количество заключенных в России находится на исторических минимумах за всю новейшую историю страны, что объясняется прежде всего интенсивной ли- берализацией уголовного наказания за нетяжкие преступления.

\section{Потенциал развития \\ производственной деятельности \\ учреждений ФСИН России}

Важными факторами производства, доступными уголовно-исполнительной системе, являются большой объем производственных площадей, а также существенный потенциал трудовых ресурсов преимущественно низкой квалификации, рыночный спрос на которые особенно высок в последнее десятилетие. Производственная деятельность осуществляется в 670 исправительных учреждениях. Доля способных к труду заключенных в системе ФСИН России составляет 64 \%. Исследователи отмечают, что потенциал развития производственной деятельности учреждений ФСИН России связан прежде всего: 1) с существенной недозагрузкой имеющихся производственных помещений; 2) с низким уровнем информированности потенциальных бизнес-партнеров о производственных возможностях учреждений системы; 3) с недостаточной эффективностью управле-

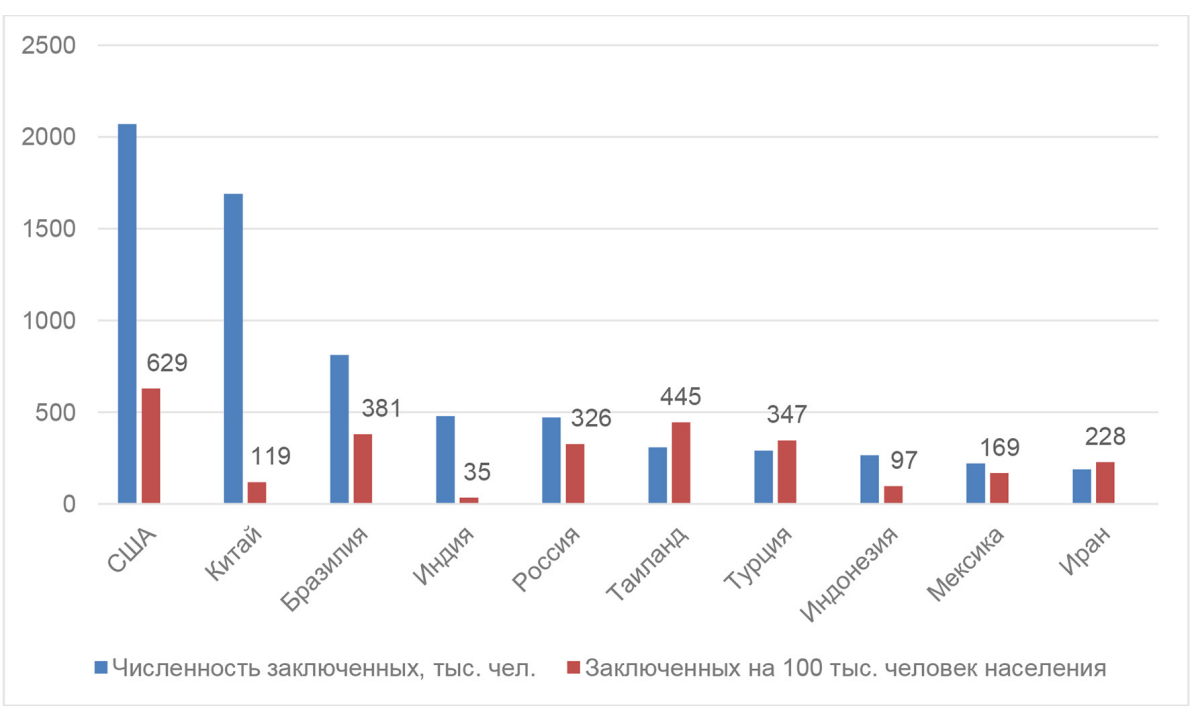

Рис. 1. Соотношение численности контингента заключенных (тыс. чел.) и численности контингента заключенных на 100 тыс. чел. населения по странам мира в 2019 г.

Fig. 1. Prison population (thousands) to prison population per 100,000 people worldwide in 2019 Source: World Prison Brief https://www.prisonstudies.org/ 
ния экономической деятельностью исправительных колоний (Ezrokh, 2017). Частичное или полное решение данных проблем необходимо для полноценной реализации задач, которые стоят перед учреждениями уголовно-исполнительной системы России.

Одной из ключевых стратегических задач развития страны на настоящем этапе признана реализация серии национальных проектов в рамках исполнения Указа Президента Российской Федерации от 07.05.2018 № 204 «О национальных целях и стратегических задачах развития Российской Федерации на период до 2024 года». Например, совокупный бюджет федерального проекта «Сохранение лесов», входящего в национальный проект «Экология», составляет 151,2 млрд руб. (3,8 \% от общего финансирования национального проекта) на период 2019-2024 гг., или около 25 млрд руб. ежегодно. За счет этих средств предполагается довести соотношение площади лесовосстановления и лесоразведения к площади вырубленных и погибших насаждений с 62,3 \% в 2018 до 100 \% в 2024 г., а также сократить оценочный ущерб от лесных пожаров почти в три раза: с 32,3 млрд руб. в 2018 г. до 12,5 млрд руб. в 2024 г. Как показывает анализ национального проекта, полноценная реализаця заданных в нем целей будет затруднительна без привлечения дополнительных ресурсов (Pyzhev, 2019). Содействие в решении данной задачи может осуществлять Федеральная служба исполнения наказаний.

Кроме того, в настоящее время важнейшее значение имеют также международные проекты. Участие России в реализации Парижского соглашения по климату 2015 г. уже сегодня требует интенсификации деятельности по реализации различных видов лесоклиматических проектов, в том числе с учетом мероприятий по лесовосстановлению и лесовозобновлению. ФСИН России может принимать все более активное участие в этой работе, осуществив серию пилотных проектов в нескольких природноклиматических зонах по всей стране. При этом необходимо исходить из принципов открытости работы над соответствующи- ми проектами и максимального привлечения иностранных экспертов, поскольку международное признание таких проектов возможно только при условии независимой экспертизы и выполнения высоких экологоэкономических и этических стандартов.

\section{Пример сотрудничества бизнеса \\ и учреждений ФСИН России \\ при реализации проектов \\ в области лесовосстановления}

Решить задачу увеличения объемов лесовосстановления в стране можно наращиванием объемов производства посадочного материала, в том числе саженцев деревьев различных пород. В соответствии с приказом Минприроды России № 1014 от 04.12.2020 с 01.01.2022 комбинированное и искусственное лесовосстановление будет осуществляться путем посадки саженцев с закрытой корневой системой не менее чем на $20 \%$ площадей, с 01.01.2025 - $30 \%$, с 01.01.2030 - $45 \%$. Таким образом, спрос на такой посадочный материал будет уверенно расти, особенно в регионах Азиатской части страны. Поскольку транспортировка саженцев на большие расстояния, как правило, оказывается нецелесообразной по экономическим и лесохозяйственным причинам, представляется логичным развитие сети лесопитомников, локализованных в местах повышенного спроса на саженцы. По некоторым оценкам имеющиеся в стране мощности лесопитомников не смогут полностью обеспечить потребность в саженцах: их дефицит составит около 92 млн шт. Покрытие данной потребности можно осуществить в том числе в рамках взаимодействия системы ФСИН и представителей реального сектора экономики лесной промышленности.

В частности, важным примером такого сотрудничества является проект, который развивается Национальной ассоциацией лесопромышленников «Русский лес» совместно с Федеральным казенным учреждением «Лечебное исправительное учреждение № 37 Главного управления Федеральной службы исполнения наказаний 


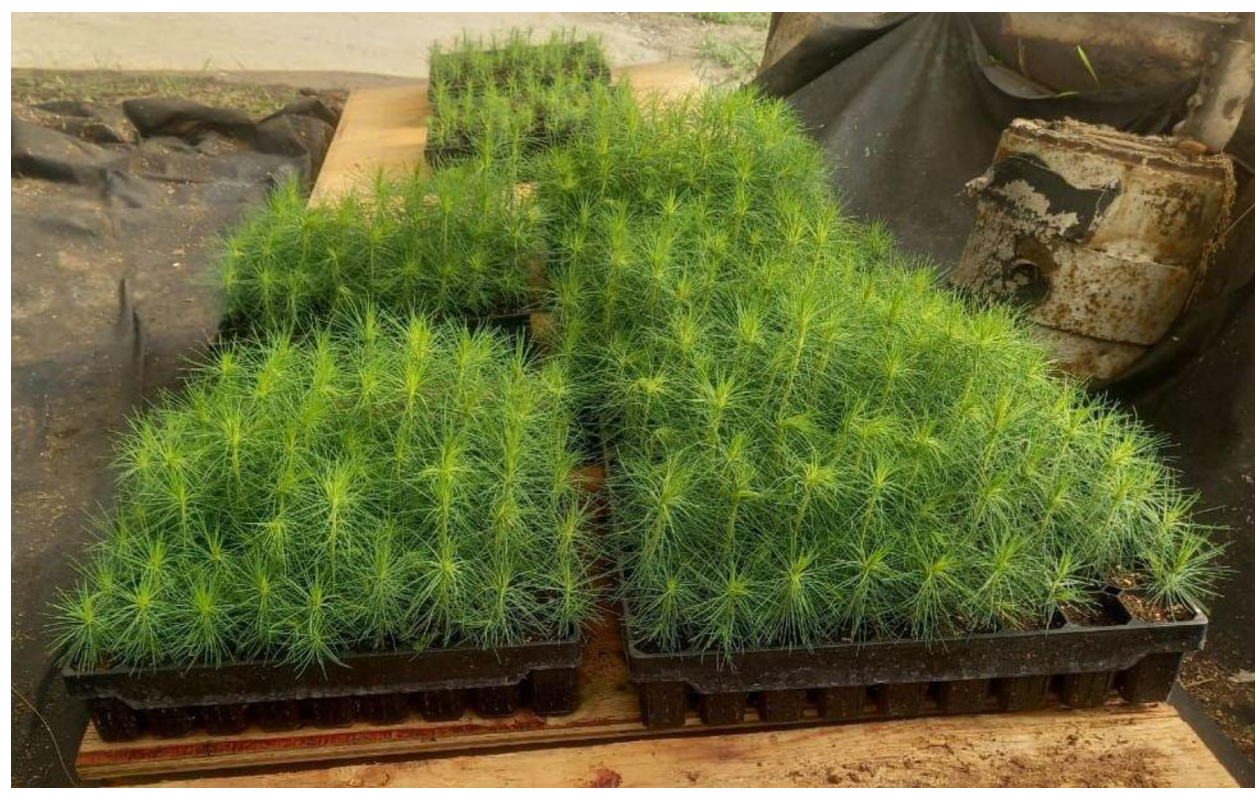

Рис. 2. Кассеты для выращивания сеянцев с закрытой корневой системой и пророщенных в них саженцев сосны

Fig. 2. General view of cassettes for growing seedlings with a closed root system and pine seedlings sprouted in them

Sources: National Association of Timber Industrialists «Russian forest», Main Department of the Federal Penitentiary Service in Krasnoyarsk Krai

по Красноярскому краю», расположенным в г. Сосновоборске Красноярского края.

Целью проекта служит создание постоянно действующего производства по выращиванию саженцев деревьев, востребованных для лесовосстановления в регионах Сибири и Дальнего Востока с учетом особенностей районирования древесных растений. На первом этапе реализации проекта в теплице общей площадью 500 кв. м проведено выращивание 162 тыс. саженцев сосны с закрытой корневой системой. Данная технология предусматривает выращивание сеянцев в специальных контейнерах (кассетах), которые изображены на рис. 2. Процент приживаемости сеянцев достигает $100 \%$ при условии, что 97,5\% достигли кондиционного размера (> $8 \mathrm{~cm})$.

Совокупные инвестиционные затраты на проект составили до 2,5 млн руб. без учета транспортных расходов и заработной платы осужденных и вспомогательного персонала. Калькуляция основных расходов на реализацию проекта представлена в табл. $1^{1}$. Общий вид теплицы с размещенными в кассетах для выращивания саженцами сосны изображен на рис. 3. Таким образом, инвестиционная составляющая себестоимости равна 11 руб. 17 коп. за 1 шт. проросшего сеянца при вложениях в размеpe 1,8 млн руб.

Заработная плата заключенных составила 25 тыс. руб. в месяц с учетом агентского вознаграждения. Всего к работам привлекались 14 заключенных. С учетом того что средний размер оплаты труда заключенных по системе исполнения наказаний не превышает 6,5 тыс. руб., данные условия труда можно признать весьма достойными и фактически сравнимыми со ставками оплаты труда за аналогичный труд

\footnotetext{
Приводится в справочных целях и не содержит расходов на обустройство водоносной скважины (до 0,5 млн руб.), потребовавшейся для локального снабжения предприятия водой с особым минеральным составом. Данные расходы могут быть избыточными в других проектах. Вместе с тем иные локации могут также потребовать дополнительных расходов другого свойства, которые будут отражаться на расчетах окупаемости соответствующих проектов.
} 


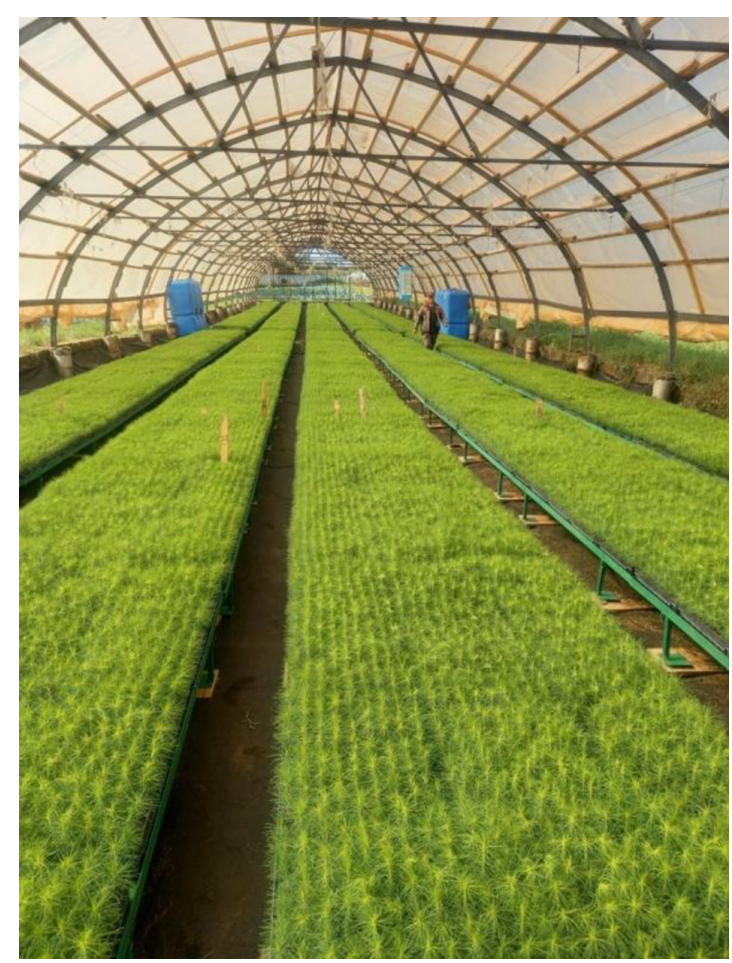

Рис. 3. Общий вид теплицы с размещенными в кассетах для выращивания саженцами сосны

Fig. 3. General view of the greenhouse with pine seedlings placed in the growing cassettes Sources: National Association of Timber Industrialists «Russian forest», Main Department of the Federal Penitentiary Service in Krasnoyarsk Krai

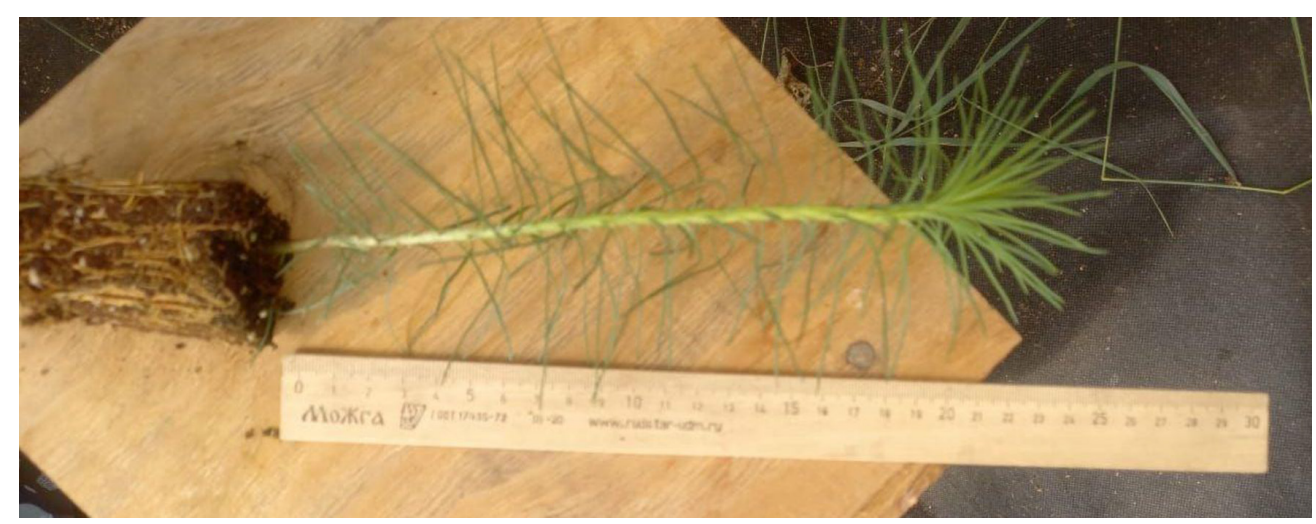

Рис. 4. Пример пророщенного саженца сосны в сравнении с мерной линейкой (см)

Fig. 4. Example of a sprouted pine seedling compared to a measuring ruler $(\mathrm{cm})$

Sources: National Association of Timber Industrialists «Russian forest», Main Department of the Federal Penitentiary Service in Krasnoyarsk Krai

для гражданского населения. Такой вывод остается справедливым и с учетом мнения о «нерентабельности» труда заключенных, занятых на традиционных для уголовно- исполнительной системы видах производственной деятельности (Ezrokh, 2017).

Сбыт готовых для высаживания саженцев (рис. 4) налажен в хозяйствах Иркут- 
Таблица 1. Примерная калькуляция затрат на устройство питомника в расчете на 162 тыс. сеянцев сосны без учета дополнительных локальных расходов

Table 1. Approximate calculation of the cost of the nursery for 162 thousand pine seedlings

\begin{tabular}{|c|l|c|}
\hline \multicolumn{1}{|c|}{ № Статья расходов } & \multicolumn{1}{|c|}{ Стоимость, руб. } \\
\hline 1 & $\begin{array}{l}\text { Многоразовые кассеты для выращивания сеянцев с закрытой корневой } \\
\text { системой }\end{array}$ & 700000 \\
\hline 2 & Оборудование (сеялка, пресс) & 195000 \\
\hline 3 & Металлоизделия для изготовления поддонов-стеллажей & 24000 \\
\hline 4 & Система полива (опрыскиватели) & 222100 \\
\hline 5 & Сырье для посадки и выращивания сеянцев & 220942 \\
\hline 6 & $\begin{array}{l}\text { Вспомогательные материалы (укрывной материал, пленка для покрытия } \\
\text { теплицы, сетка для затенения, строительный материал) }\end{array}$ & 1811151 \\
\hline & ИтОГО & \multicolumn{1}{|c|}{} \\
\hline
\end{tabular}

ской области. Потребность Красноярского края в 2022 г. оценивается в 4 млн шт., к 2025 г. - до 7 млн шт.

По состоянию на конец 2021 г. рыночная стоимость готового к продаже саженца сосны составляет 20-25 руб. По прогнозу Ассоциации, в 2022 г. стоимость саженцев достигнет 40-45 руб. за штуку с учетом увеличения спроса. Таким образом, при условии наращивания объемов производства и соответствующем снижении удельных затрат на единицу продукции предприятие сможет обеспечить высокую рентабельность и низкие сроки окупаемости проекта. Этот факт подчеркивает экономическую эффективность организации лесопитомников по выращиванию саженцев с закрытой корневой системой.

Также следует отметить, что на базе ГУФСИН по Свердловской и Нижегородской областям организовано выращивание саженцев с открытой корневой системой в количестве 430 тыс. шт. в год.

Руководством ФСИН России запланировано дальнейшее тиражирование описанного опыта в исправительных учреждениях не только Красноярского края, но и других регионов страны.

Другим перспективным направлением может быть привлечение осужденных на принудительные работы на объектах различных предприятий и организаций с созданием на их базе исправительных центров. Около 80 \% лиц, отбывающих наказания в исправительных центрах, - это осужденные, которые доказали своим поведением в местах лишения свободы, что встали на путь исправления, готовы вернуться в общество к нормальной трудовой жизни и восстановить социальные связи.

\section{Заключение}

Совершенствование модели деятельности уголовно-исполнительной системы России требует новых подходов и новых задач, направленных на развитие системы исправительных учреждений не только в целях изоляции лиц, преступивших закон, но и их привлечения к общественно полезному труду в интересах национальной повестки социально-экономического развития.

Одним из перспективных направлений привлечения осужденных к труду является проведение работ по лесовосстановлению, в том числе в рамках разворачивающейся деятельности по выполнению национальных обязательств в рамках Парижского климатического соглашения. Внесенные изменения в отраслевое законодательство в сфере лесного хозяйства предусматривают существенное наращивание объемов искусственного лесовосстановления с использованием саженцев с закрытой корневой системой в ближайшие годы. В статье подробно проанализирован опыт реализа- 
ции в Красноярском крае совместного пилотного проекта по созданию лесопитомника на базе одного из учреждений ФСИН при участии бизнес-ассоциации в сфере лесной промышленности. Установлено, что проект не только результативен, но и имеет высокие показатели экономической эффективности, характеризуется низкими сроками окупаемости при обеспечении достойных условий труда осужденных.

Описанный опыт может тиражироваться не только в смысле уже заложенного в планы ведомства наращивания производственных мощностей, но и в смысле расширения видов работ, к которым могут быть привлечены заключенные: например, осужденных можно привлекать к сбору и подготовке семян лесных древесных пород и посадке саженцев с последующим уходом за лесными угодьями.

Следует подчеркнуть, что реализация описанных инициатив требует су- щественного расширения взаимодействия уголовно-исполнительной системы с научно-образовательным комплексом страны, в том числе в рамках действующих и перспективных программ Минобрнауки. Примером подобного рода эффективного взаимодействия могло бы стать включение определенных направлений деятельности в работу флагманских проектов в рамках научно-образовательных центров мирового уровня ${ }^{2}$, в том числе научнообразовательного центра «Енисейская Сибирь», созданного Красноярским краем, Республикой Хакасия и Республикой Тыва.

\footnotetext{
2 Реализуется в соответствии с постановлением Правительства Российской Федерации от 30 апреля 2019 г. № 537 «О мерах государственной поддержки научнообразовательных центров мирового уровня на основе интеграции образовательных организаций высшего образования и научных организаций и их кооперации с организациями, действующими в реальном секторе экономики».
}

\section{Список литературы / References}

Abutalipov, A.R., Abutalipova, L.N., Kalimullina, O.A., Fakhrutdinova, A.V., \& Getmanskaya, M.Y. (2020). Sociological analysis of social and psychological resources of Russian post-penitentiary system through the example of multicultural regions. In Contributions to Economics, 351-362.

Bair, A.P. (2007). Prison labor in the United States: An economic analysis. Routledge, 2007.

Bohatyrova, O., Bohatyrov, I., Bohatyrov, A., Hrytsaienko, L., \& Yermakova, G. S. (2020). Criminological Analysis and Its Economic Aspect of the Crime Rate in the Places of Confinement of Ukraine for the Last Decade (2010-2019). URL: https://papers.ssrn.com/abstract $=3632787$

Connelley, W.L., Conklin, N.C., Gordon, R.S. (1993). Can prison farming be profitable? The case of Arizona correctional industries. In Agribusiness, 9 (3), 257-279.

Das, D., Sarma, B. (2020). Prison labour in colonial India: A case study of Assam In Space and Culture, India, 8 (1), 91-100.

Ezrokh, Yu.C. (2017). Production Potential of the Modern Russian Penitentiary System: Status and Measures for Development. In Journal of the New Economic Association, 3 (35), 126-143.

Gallagher, D.J., Edwards, M.E. (1997). Prison industries and the private sector. In Atlantic Economic Journal, 25 (1), 91-98.

Giles, M., Le, A.T. (2007). Prisoners' labour market history and aspirations: A focus on western Australia. In Econ. Rec. 83 (260), 31-45.

Lamasharipov, D., \& Others. (2018). Risk Management and Prospects for the Transition of Penitentiary System: The Case of Kazakhstan. In European Research Studies Journal, 21(3), 488-495.

LeBaron, G. (2008). Captive labour and the free market: Prisoners and production in the USA. In Capital \& Class, 32 (2), 59-81.

Miller, M., Smith, J.C. (2015). In the shadow of the Gulag: Worker discipline under Stalin. In J. Comp. Econ, 43 (3), 531-548.

Pryor, F.L. (2005). Industries behind bars: An economic perspective on the pro-duction of goods and services by U.S. prison industries. In Review of Industrial Organization, 27 (1), 1-16. 
Pyzhev, A.I. (2019). The forest complex of Russia through the mirror of the May 2018 Presidential Decree: is it worth waiting for a breakthrough? In Journal of Economic Regulation, 10 (1), 77-89.

Schmidt, E., \& Van de Walle, S. (2020). Defending, prospecting or reacting? Strategic management during cutbacks in the Dutch penitentiary sector. In Financial Accountability and Management, DOI: 10.1111 /faam.12271

Scott, C.E., Derrick, F.W. (2006). Prison labor: The local effects of Ohio prison industries. International Advances in Economic Research, 12 (4), 540-550.

Sedikh, V. et al. (2020). Public-private partnership as an instrument ensuring food security of penal institutions. In IOP Conf. Ser.: Earth Environ. Sci. 548 (8), 082074.

Timofeeva, E.A. (2020). Foreign Private Prisons: Historical and Economic Is-sues of Management and Performance. In Growth Poles of the Global Economy: Emergence, Changes and Future Perspectives. Ed.: E. G. Popkova. Cham: Springer International Publishing, 1105-1113.

Vilkova, A.V., \& Timofeeva, E.A. (2018). Socio-economic stratification and the penitentiary system. URL: https://www.ersj.eu/journal/1113/download 